\title{
Enhancing the foundations for theorising through bibliometric mapping
}

\author{
Noemi Sinkovics \\ Alliance Manchester Business School, \\ The University of Manchester, Manchester, UK
}

\begin{abstract}
Purpose - The "academic revolution" that has taken place over the past 50-60 years has brought about many opportunities, but also challenges, in the lives of academics. The "publish or perish" phenomenon can be seen as one manifestation of the heated competition among universities for talent and resources. The resulting increase in publications, the decrease in the time academics have to read them, together with editors' call for more originality, innovation, and meaning in submitted manuscripts lead to two questions. What techniques can help researchers and $\mathrm{PhD}$ students to effectively and efficiently navigate through large bodies of literature? What tools and techniques can be used to enhance the foundations for theorising? The purpose of this paper is to answer these two interrelated questions.

Design/methodology/approach - The abstracts of 410 peer-reviewed journal articles connected to ethics in (international) marketing research are explored with software tools. The freely available VOSviewer software is used to visualise the specified body of literature. NVivo is employed to go deeper and explore specific themes identified through VOSviewer.

Findings - A total of 17 clusters were identified, representing the major themes in the selected body of literature. Additionally, a number of research avenues and research questions are presented.

Research limitations/implications - The analysis is based on the information provided in abstracts. Future research may wish to extend the analysis to full articles.

Originality/value - The paper contributes by demonstrating how software tools such as VOSviewer and NVivo can be used to explore large bodies of literature and to experiment with research ideas to enhance the foundations for theorising.
\end{abstract}

Keywords Marketing, Nvivo, International marketing, Bibliometric mapping, Theorising, VOSviewer Paper type Research paper

\section{Introduction}

The "academic revolution" that has taken place over the past 50-60 years (Altbach et al., 2010) has brought about many opportunities, but also challenges, in the lives of academics. The "publish or perish" phenomenon (e.g. de Rond and Miller, 2005) can be seen as one manifestation of the heated competition among universities for talent and resources. According to data from the Higher Education Statistics Agency, the total number of academic staff employed at UK higher education institutions increased from 114,721 in 1995 to 185,585 in 2013. However, the number of high-quality journals

(C) Noemi Sinkovics. Published by Emerald Group Publishing Limited. This article is published under the Creative Commons Attribution (CC BY 3.0) licence. Anyone may reproduce, distribute, translate and create derivative works of this article (for both commercial \& non-commercial purposes), subject to full attribution to the original publication and authors. The full terms of this licence may be seen at http://creativecommons.org/licences/by/3.0/legalcode

Financial support from the Economic and Social Research Council (ESRC) Impact Acceleration Account (ESRC-IAA), [R118569], is gratefully acknowledged.

Foundations for theorising

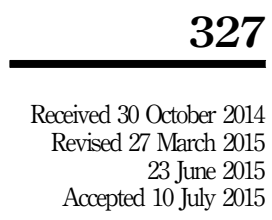

Accepted 10 July 2015 
IMR

33,3 offering publication space has not grown in proportion with the surge in the number of academics. Although the recently released Academic Journal Guide (2015) prepared by the Association of Business Schools saw an 88 per cent increase in the number of journals included, the number of three and four star journals within different areas remained proportionately about the same. This is all the more relevant since the pressure to publish in journals rated three and above is becoming stronger. This development is not without negative side effects.

The pressure to publish, in general, and the sense of urgency regarding placing one's work in high-quality journals in particular, has led to a number of unintended consequences. Miller et al. (2011) find that it may not only induce heightened stress levels and publication burn-out, but in nearly 50 per cent of the surveyed cases it hindered creativity and the use of alternative research paths. This latter point is corroborated by Lee and Greenley's (2009) observation that journals often publish less creative but well-written articles. At the same time, editorials on what contributes a meaningful or significant contribution usually stress the importance of theory development and originality (e.g. Sutton and Staw, 1995; Weick, 1995). Svensson and Wood (2008), furthermore, explain the difference between top and leading journals based on, among other things, whether the research problem of an article is challenging, unorthodox, and goes beyond technicalities and repetitions of previous research. From these findings and observations a paradox is starting to crystallise. The unintended consequences of the "publish or perish" phenomenon do not only include physical and mental health issues. On a much deeper level, these pressures seem to affect the attainment of the very goal being pushed for in the first place, that is, the generation of relevant, interesting and original research which is either based on a strong theory or on exploring new and exciting ideas in the form of theorising. An additional consequence of this development is the exponentially growing number of publications to be sifted through. Doing so by traditional methods is an increasingly challenging task (Sinkovics, 2013).

It must be noted that this paper does not claim that all papers that are published in high-quality journals lack imagination and creativity. Neither is it aimed at evaluating or criticising research policy. Instead, what it aims to do is to suggest ways in which scholars can preserve their creativity amidst the pressures they face. To this end, two questions present themselves. First and foremost, what techniques can help researchers and $\mathrm{PhD}$ students effectively and efficiently navigate through large bodies of publications? Second, what tools and techniques can be used to enhance the foundations for high-quality theorising (Svensson and Wood, 2008)? In an attempt to answer these questions, the present paper demonstrates how software tools can be deployed to explore bodies of literature through visualisation. Furthermore, it provides an example of how selected software tools can be used for the identification of potentially interesting research questions that in turn can lead to the formulation of interesting and relevant problem statements.

\section{The promise of technology}

This section will explore the promise of technology as an aid to answering the research questions presented in the introduction. However, in order to fully understand how technology can serve us, it is necessary to spend some time discussing how theories come into existence. As the purpose of the paper is not to write an essay on theory building, but on how software tools can enhance the foundations for theorising, this discussion will be kept as short as possible. Weick (1989) suggests that, in order to understand theory 
building, it is important to identify and describe its stages. However, while it is possible to roughly divide theory construction into the three stages of problem statement, thought trials, and selection criteria (see Weick, 1989), these stages should not be regarded as parts of a linear process. Rather, theorists need to be able to engage in simultaneous parallel processing (see Bourgeois, 1979). Weick (1995) furthermore accords great importance to the distinction between theorising and theory building. Theorising can be broadly defined as the intuitive, blind, wasteful, serendipitous, and creative phase within theory building that is often expressed in discursive form (see Weick, 1989). This differentiation is very important for the following reason.

Books with "theory building" (e.g. Dubin, 1969; Shoemaker et al., 2003) or "theory construction" (e.g. Jaccard and Jacoby, 2010) in their title often assume a more or less completed theorising phase and thus focus on the technicalities of model building and testing. Whether authors build on the assumption that models are a special type of theory, a simplified version of theory, or are synonymous with theory (see Jaccard and Jacoby, 2010), what many of them have in common is that they let theory building be dictated by methodological rigidity that prioritises validation over usefulness (Lindblom, 1987; Weick, 1989). Arguably, this can have a very important unintended consequence for new generations of researchers. Merely assuming a completed process of theorising, without explicitly mentioning it, may leave the impression that building elaborate models is the same as building useful theories. This in turn may lead to an array of methodologically over-engineered papers that make limited theoretical contributions (see Rosemann et al., 2006).

Weick (1989) suggests that one can improve the quality of theories by introducing disciplined imagination at each stage of theory construction. At the core of disciplined imagination is the attempt to recognise and transcend one's self-interest, to identify and challenge one's own as well as the discipline's assumptions, and to find ways to increase the independence of selection processes. To demonstrate how disciplined imagination works, Weick (1989) compares the theory building process to night-time marine navigation by radar. Whether or not a ship collides with an object or another ship depends on the selection process of the captain. He will observe objects or phantom reflections on his radar and decide which obstacles need to be avoided and which ones do not pose any danger. Theory building is similar to this process as the researcher also needs to use selection processes in order to decide which conjectures are of interest to him. Whether or not a context, a concept, or a conjecture is deemed as interesting is, among other things, a function of whether it triggers the researcher's imagination and intuition (see Kaplan, 1964, p. 15).

A selection process based on interest represents an alternative path to the above mentioned model building approach driven by validation and methodological excellence. Weick (1989) proposes that when one finds something interesting it is in fact a sign that one's past experience has been disconfirmed by one's current experience. The feeling of interest represents the start of an unmasking process, namely, the unmasking of one's own assumptions or even the unmasking of a whole discipline's assumptions. This is more or less in line with what Alvesson and Karreman (2007) call mystery construction. The essence of mystery construction is the identification of breakdowns in our understanding. To this end, the analogy of marine navigation at night is more relevant than ever before. The 25 years that have passed since the publication of this metaphor have seen significant technological advancements. The present paper builds on Weick's (1989) suggestion of deploying devices to enhance the quality of theorising through the increased independence of
Foundations for theorising 
IMR

33,3

330 selection processes. Current software packages not only allow implementation of Weick's (1989) suggestions, but also offer the possibility of going beyond them.

To this end, the promise of technology for theory construction can be delineated as follows. First, software tools can help scholars visualise large bodies of literature in order to detect major trends and overarching themes. Furthermore, literature maps can be used to aid the brainstorming process leading up to the formulation of alternative research questions. Scholars can generate a list of concepts from term maps based on the "that's interesting" criterion (see Weick, 1989, p. 525). Using literature maps as a stimulus for brainstorming instead of simply relying on one's memory ensures the researcher's exposure to a large pool of automatically created concepts and relationships. Also, the opportunity to look at concepts in relation to other concepts allows the researcher to bring his/her assumptions to the surface and to increase the accuracy of the concepts' representation. Second, qualitative data analysis software tools can be used to document thought trials and selection processes in the form of code structures, memos, visual representations, etc. In this way, theorists can not only ensure that the theorising process benefits from increased heterogeneity and increased independence of the selection processes, but it is also possible for the whole process to be documented.

While the promise of technology is of relevance for the whole theory construction process, the present paper only aims at demonstrating how software tools can support the identification of alternative research questions. It must be reiterated that technology merely represents an aid to the process and it is in no way suggested that it replace or reduce the researcher's involvement. The next section will give a brief overview of common techniques for complexity reduction and visualisation, followed by a description of the selected software tools.

\section{A broad overview of common techniques and software selection}

The proliferation and success of tools that allow academics to explore and analyse bodies of literature can be seen as an indication that there is indeed a need to reduce complexity. For example, the Web of Science ${ }^{\mathrm{TM}}$ offers built-in citation reports and a function that helps categorise research outputs in different ways. In addition to its reference management function, Mendeley permits academics to interact with each other. At the same time, by using crowdsourcing, the platform also provides insights into real-time research trends. Another example of an attempt to tackle the challenge of complexity is the use of bibliometric analysis methods to map research fields.

In order to gain insight into the frequency with which bibliometric methods are used in marketing, a search was conducted. The search terms included bibliometrics, bibliometric analysis, marketing, and international marketing. Papers published in non-marketing journals were discarded, with the exception of two articles that were explicitly marketing related. The search yielded eight results. This relatively small number of studies indicates that the field does not yet take full advantage of what these techniques have to offer. Table I provides an overview of the papers.

The identified articles cover the following techniques. Samiee and Chabowski (2012) use exploratory factor analysis, hierarchical cluster analysis and metric multidimensional scaling to explore the knowledge structure in international marketing between 1999 and 2008. Chabowski et al. (2013) apply co-citation analysis and multidimensional scaling to explore the global branding literature. Munoz-Leiva et al. (2013) use co-word analysis combined with performance analysis and science mapping to identify and visualise the most prominent themes in financial marketing between 1961 and 2010. Despite certain differences in the particular methods applied, the commonality between these eight 
Authors/year/

journal

Munoz-Leiva $e t$ al.

(2013), Service

Industries Journal

Chabowski et al. (2013) Journal of

International

Business Studies

Zhu and Guan

(2013)

Scientometrics

Samiee and

Chabowski (2012)

Academy of

Marketing Science

Backhaus et al.

(2011) Industrial

Marketing

Management

Chabowski et al.

(2011) Journal of the

Academy of

Marketing Science

Baumgartner

(2010) Journal of

Consumer

Psychology

Hoffman and

Holbrook (1993)

Journal of

Consumer Research
Area and period

Method

Purpose

Identification of general trends, priority themes 84 papers $(1961-2010)$

Global branding 27

highly cited papers (2000-2010)

Service innovation 437 Keyword co-occurrence papers (1992-2011) network analysis

International

marketing 3,632

papers (1999-2010)

B2B marketing 1,392

papers (1997-2009)

Sustainability in

marketing 1,320

papers $(1958-2008)$

Consumer research Citation analysis

48 papers (1936-2009)

Exploratory factor analysis, hierarchical cluster analysis, metric multidimensional scaling Citation and co-citation analysis, co-citation networks

Co-citation analysis and multidimensional scaling

Author co-citation in the Journal of

Consumer Research

42 authors (1974-1989)

Most highly cited global branding articles, major themes

Most popular keywords, researchers with largest trends and mainstream research

Knowledge structure in international marketing in B2B marketing

Exploring the history of consumer research analysis, symmetric and structure of the field asymmetric properties
Foundations for theorising contribution, identification of

Key players and key papers

The intellectual structure of sustainability research in marketing and major themes

Author co-citation Exploring the intellectual
Table I.

Bibliometric studies published in marketing journals

studies is that they all focus on major trends in the form of most-cited studies or most frequently used terms. While this is an excellent method for identifying mainstream research themes (Zhu and Guan, 2013), emerging themes or potentially interesting themes on the margins of a field may not be easy to detect.

To this end, Sinkovics (2013) proposes that software tools that were originally designed to detect trends can also be used for generating new research ideas. For example, multidimensional scaling outputs can be used to examine the distances between concepts and to start thought experiments on potential new relationships between concepts or on previously unthought-of combinations of concepts. However, while the CATPAC ${ }^{\mathrm{TM}}$ software package explored in Sinkovics' (2013) study can be deemed as promising, the software's limited visualisation ability makes the results difficult to read. Also, although multidimensional scaling is the most popular distancebased method for constructing bibliometric maps of concepts or co-citation networks (Van Eck and Waltman, 2010), there are other methods that can be explored. Such methods include the VOS mapping technique (e.g. van Eck et al., 2006), the VxOrd 
IMR

33,3

332

method (Klavans and Boyack, 2006), and the Kopcsa and Schiebel (1998) method. At this point, it must be emphasised that this paper is in no way intended to be a technical or mathematical discussion of the underlying algorithms.

As one can see from the above description, a variety of techniques are available that have the potential to reduce complexity by detecting trends, but only a limited number of suggestions exist as to how to use bibliometric output maps as a starting point for theorising (see Sinkovics, 2013). Similarly, a variety of software packages can be used for visualisation. While providing a comprehensive list of tools and a discussion of their respective merits and limitations would add value to this paper, due to space limitations such a discussion remains outside its scope. The main selection criteria for the techniques and software packages used here were the following. The chosen technique(s) needed to have the potential to facilitate both complexity reduction in large bodies of literature and theorising. The software packages were required to be user friendly, flexible, and allow for high-quality visualisation. Based on these criteria, VOSviewer and NVivo were chosen. It must be noted that the method outlined in this paper is not dependent on the use of particular software packages. As long as a software package delivers on the above criteria, it can be deemed suitable for carrying out such analysis. The following section gives a brief overview of the two packages that were selected for this particular paper. It also needs to be noted that both software packages are continuously updated and improved by the developers. While this may lead to changes in the user interface of the packages, the basic principles outlined in this paper will remain unaffected.

\section{VOSviewer and NVivo - how do they work?}

VOSviewer employs the VOS (visualisation of similarities) mapping technique and is freely available (www.vosviewer.com). It can be used to create maps either based on a text corpus or based on networks such as citation networks. The present paper employs the former method. While creating publication maps would also yield important insights into a literature body, this is outside the scope of this study. The second software package selected was NVivo. Here, again, one has several software packages at one's disposal. NVivo was chosen for its user friendliness, its built-in model building function, and the possibility of creating a flexible code structure (also referred to as nodes). While VOSviewer serves as an excellent tool for mapping a body of literature and spotting potentially interesting concepts, NVivo can be used to explore the context of those concepts and to experiment with relationships between concepts. The two tools complement each other very well. The following two sub-sections will provide a brief introduction into how these two software packages work.

\section{VOVviewer}

Van Eck and Waltman (2010) offer a detailed review of the VOSviewer software which is freely available at www.vosviewer.com. The main advantage of the software is the high quality of its visual representation. It allows users to explore the maps in detail by offering zooming and scrolling options. Another advantage is the tool's capability of mapping a large number of items, i.e. 100 or more. At this point it needs to be mentioned that if users wish to visualise a large number of concepts (5,000 or more) they will need a computer with a relatively capacious internal memory. Maps are created based on a co-occurrence matrix. First, a similarity matrix is calculated using the association strength measure (van Eck and Waltman, 2007). This is a requirement for the application of the VOS mapping technique. Second, the VOS mapping technique is 
applied. The final step involves the translation, rotation, and reflection of the results in such a way that they are consistent. Van Eck and Waltman (2010) provide an in-depth discussion of these three steps for the interested reader.

The user can create a map based on a network or a text corpus. In this paper, the latter technique is applied. Data for both approaches can be downloaded directly from the Web of Science ${ }^{\mathrm{TM}}$. To create the text corpus file, users need to download the abstracts or other parts of selected papers into a text file in which each row represents a paper. Once the data have been transformed into a visual form, VOSviewer offers two for theorising ways of displaying them: network visualisation and density visualisation. The network visualisation view displays concepts based on their importance. The larger the label and the circle, the more important is the concept. The colour of the circle indicates to which cluster the term belongs. However, in order to avoid overlapping labels only a subset of labels is represented on the map. The viewer can then zoom in on the concepts to explore them in more detail. The more the viewer zooms in, the more concepts become visible. The density visualisation view indicates the importance of areas on the map based on the number of connected items. Within the density visualisation, one can opt for the cluster density view. The cluster density view indicates the assignment of items to clusters and their density.

When producing concept maps based on a text corpus, the user can choose between binary counting and full counting. When choosing binary counting only the presence or absence of a term in a document is counted, not the total number of occurrences within a document. In the case of full counting all the occurrences are considered. In this paper both options have been explored.

\section{NVivo}

As in the case of VOSviewer, there are also detailed manuals and reference guides available for NVivo (e.g. Richards, 1999). The present section is only intended to provide a very brief overview of what the software can do. NVivo provides a range of tools for organising data and analysing it in a flexible manner. It is capable of storing different types of data from transcribed interview texts over videos and images to bibliometric information imported from reference manager software. Newer versions of the software can even import data from social networking sites such as Facebook and LinkedIn. NVivo is "designed to remove rigid divisions between data and interpretation [...] [and] offers many ways of connecting the parts of a project, integrating reflection and recorded data” (Richards, 1999, p. 4).

Researchers can create elaborate node structures that can subsequently be changed and/or reshuffled. It is possible to run different types of queries ranging from the identification of single terms to elaborate matrix queries used to detect patterns. The model builder function can visualise selected nodes, predefined relationships, the sources of the data contained in individual nodes, and much more. For larger projects the software allows several coders to work on the same data file. To sum up, NVivo is a software tool that helps researchers to manage and synthesise their ideas (Richards, 1999; Sinkovics et al., 2008; Sinkovics and Alfoldi, 2012). As a consequence, it is a valuable tool not only for qualitative data analysis but also for theorising (see Bringer et al., 2006).

\section{Method}

The method outlined in this section can be divided into four phases. Figure 1 offers a step-by-step guide to each phase. 


\section{IMR}

33,3

\section{4}

Figure 1

Step-by-step guide through the analysis process

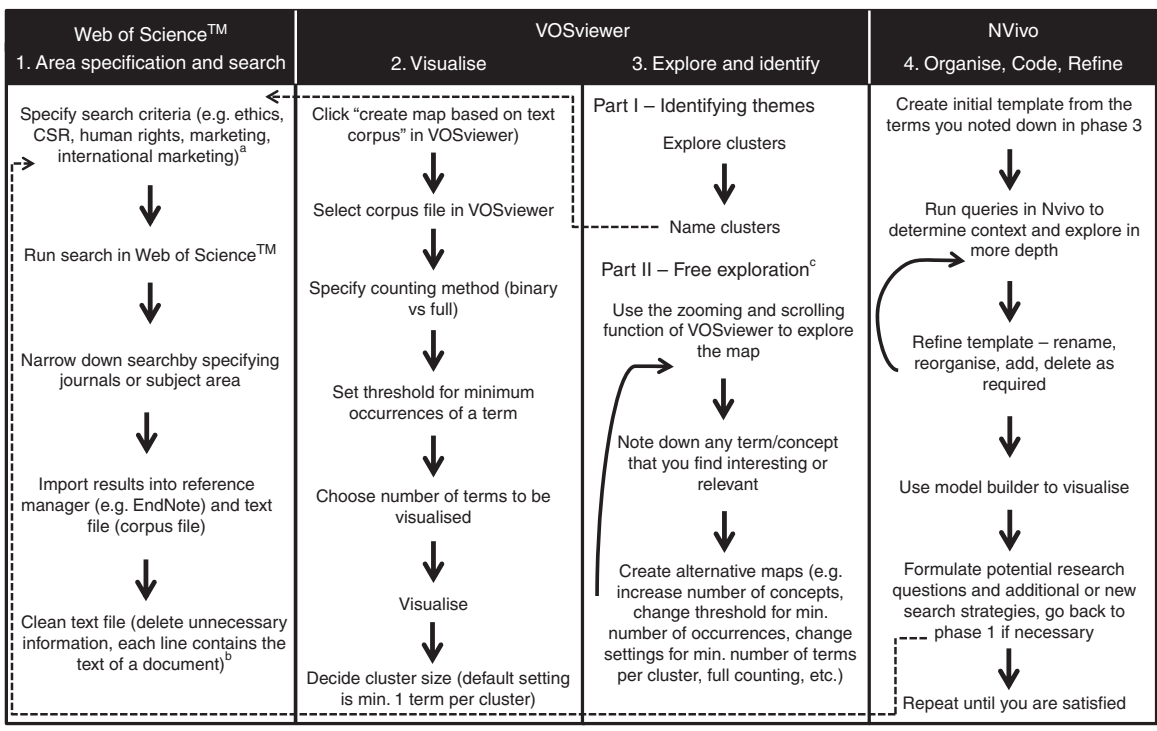

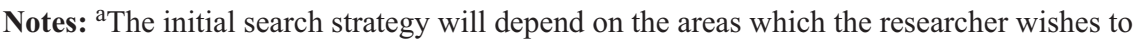
explore. This will be refined throughout the iterative process; ${ }^{b}$ VOSviewer 1.6.4 offers the option to exclude copyright statements and also supports other formats such as Scopus and RIS; cthis is the part within the process where the researcher uses the term map as the radar from Weick's (1989) night-time marine navigation metaphor

Phase 1 encompasses the specification of an initial search strategy and the collection of data. In this study, the data consist of the titles and abstracts of selected journal articles. For the purpose of this study, the area of enquiry specified was ethical issues in marketing. To keep the search as broad as possible, a search strategy consisting of related terms was created, including terms such as CSR, human rights, ethics, and ethical. The Web of Science ${ }^{\mathrm{TM}}$ was used to identify articles related to those terms. Table AI shows the initial search strategy (the syntax was copied and pasted directly from the Web of Science ${ }^{\mathrm{TM}}$ ). The first search yielded 14,747 papers. This large number was due to the inclusion of journals from a wide range of disciplinary areas such as law, medicine, nursing, etc. In order to keep the findings within the area of marketing, the search was narrowed down, the results being limited to journals related to marketing and international marketing. The names of the journals are listed in Table AI. This second search yielded 410 articles that form the body of literature explored in the rest of this paper. Next, the titles and abstracts were exported to EndNote (reference manager software) and a text file (also called the corpus file).

Phase 2 involved the visualisation of the text corpus consisting of the 410 abstracts identified in phase 1 . The purpose of this phase is to generate an overview of the concepts within a given body of literature. In VOSviewer the option "create map based on text corpus" was selected. Next, the corpus file (text file) was located and the counting method was set to binary counting. This means that each concept is only counted once per abstract irrespective of how many times it actually occurs in a given abstract. The minimum threshold was set at two occurrences so that a large number of concepts would be included on the map. The number of concepts automatically selected 
by the software to be included in the visualisation was 846 . VOSviewer's algorithm automatically excludes the 40 per cent least relevant terms. It uses a natural language processing technique when extracting terms from the text corpus file. A term is defined as a sequence of nouns and adjectives ending with a noun (van Eck and Waltman, 2015). Finally, the term map was created. The cluster size was left at the default setting of a minimum of one term per cluster. The resolution parameter was left at its default value of one.

Phase 3 consists of two parts. Part 1 is aimed at demonstrating how software tools

can help reduce complexity in large literature bodies. To this end, the cluster density view of VOSviewer can be used to explore the generated clusters. Furthermore, the "items" tab within the software allows the complete list of concepts per cluster to be viewed. One can then look at the list and simultaneously use the zooming and scrolling functions of the software to explore the clusters and find suitable titles for each cluster. Part 2 of phase 3 uses VOSviewer for a different purpose. Here, the focus is on answering the second research question about how software tools can help to identify interesting ideas as a starting point for theorising. Just as the marine navigation tool from Weick's (1989) metaphor helps ship captains to decide which objects are dangerous, the zooming and scrolling functions of VOSviewer can be used to identify concepts that trigger the researcher's imagination, creativity, and intuition. Any concept/term that captures one's attention should be noted down. In order to increase the pool of concepts, one can create alternative maps by increasing the number of concepts included, and changing settings such as the minimum threshold of occurrences of a term. In this study, an additional visualisation was run in which the threshold for the minimum number of occurrences was set at 1 and the number of concepts included in the visualisation was set at 6,000. This step was carried out with both binary and full counting.

Phase 4 involved a more structured exploration of the text corpus (the 410 abstracts) based on the terms/concepts noted down in phase 3 . These terms/concepts can be regarded as the result of a visual brainstorming. To carry forward the marine navigation metaphor, now that the captain has identified which dots on the radar screen are potentially dangerous, he needs to investigate them more carefully. NVivo offers a very useful platform for such an investigation. The list of terms/concepts identified in VOSviewer can form an initial coding template (for more information see King, 1998). The abstracts and other reference details were imported into NVivo from EndNote (one could use any other reference manager software). The researcher can then run queries to explore the context of the individual concepts by looking at the surrounding paragraphs in which the concepts occur. This contextual analysis can also help to identify potential relationships between two or more concepts. Through this in-depth investigation, the initial template will be refined and reorganised. The model builder function of the software can be used to visualise selected nodes. This can form the basis for the identification of research questions or new search strategies. If necessary, one can go back to phase 1 and repeat the whole process again with a different search strategy. Table AII presents the node structure from this study, which includes 203 items.

\section{Results}

In this section words "terms" and "concepts" are used interchangeably. As reported in the previous section, in phase 2 of the analysis, 846 concepts were included in the visualisation. The VOSviewer map yielded 17 concept clusters. As mentioned above, 
IMR

33,3

336

the threshold for the minimum number of terms per cluster was left at 1 . While generally it may be preferable to keep the number of clusters at a minimum, in this study the purpose was to identify as many themes as possible. After investigating the concepts in each cluster, it was deemed important not to reduce the number of clusters. Figure 2 shows the cluster density view of the concept map. The colour coding of the clusters (see Figure 2) together with VOSviewer's built-in function for viewing the list of concepts in each cluster was used to arrive at generalisations about the clusters so as to capture their overarching themes. Table II lists the name of the themes derived from the cluster density view and the cluster term lists. This process correspond to part 1 of phase 3 in the step-by-step guide depicted in Figure 1. The following paragraph will give a detailed overview of the identified themes.

Cluster 1 is centred on themes around consumers' reactions to firms' CSR activities as well as around ethical consumer behaviour. Cluster 2 is concerned with topics connected to branding in general and to the brand-CSR relationship in particular. Cluster 3 can be labelled as ethical issues and CSR in a global context. It also contains issues related to theory development. Cluster 4 is focused on matters around accountability, authenticity, and stakeholder management. Cluster 5 brings together topics concerning firms' social and financial performance. Cluster 6 is concerned with labour rights and buyer-supplier relationships. Cluster 7 focuses on topics connected to corporate image and related consumer action. Cluster 8 is centred on corporate ethical decision making and its consequences. Cluster 9 comprises consumer loyalty issues. Cluster 10 encompasses topics concerned with cognitive moral development as well as models of ethical behaviour. The focus of cluster 11 is on ethics in an online context. Cluster 12 focuses on fairness issues and sustainable consumption. Cluster 13 is related to business communities in local economies. Cluster 14 focuses on the determinants of ethical work climate and job satisfaction. Cluster 15 brings together topics connected to consumer lifestyle and consumer empowerment. Cluster 16 is concerned with corporate

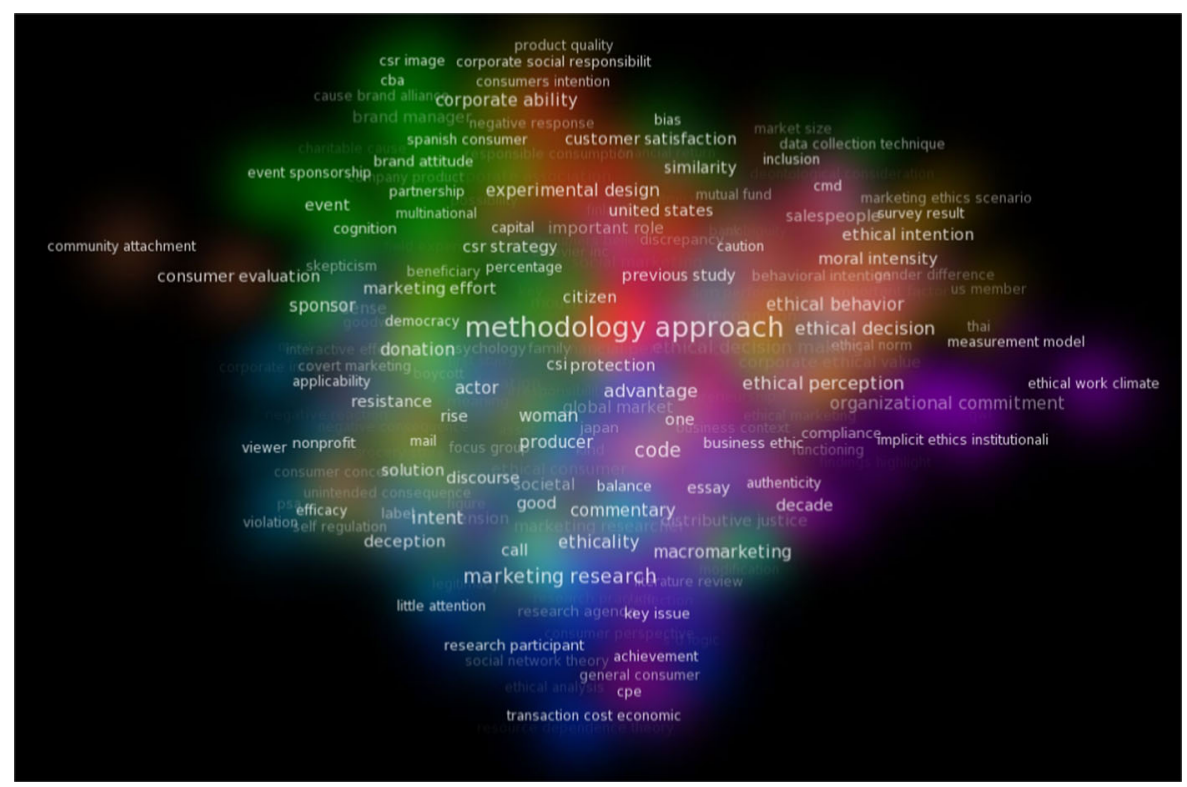

Figure 2.

Cluster density view of the visualisation of 846 concepts (step 1) 


\begin{tabular}{|c|c|c|c|}
\hline & Name & $\begin{array}{l}\text { Number of } \\
\text { concepts }\end{array}$ & $\begin{array}{l}\text { Foundations } \\
\text { for theorising }\end{array}$ \\
\hline Cluster 1 & $\begin{array}{l}\text { Consumers' reactions to firms' CSR activities, consumption-related } \\
\text { ethical issues, consumers' behavioural intentions }\end{array}$ & 85 & \\
\hline Cluster 2 & Impact of branding and CSR on consumer perceptions & 79 & \\
\hline Cluster 3 & Ethical issues and CSR in a global context and theoretical development & 73 & 22 \\
\hline Cluster 4 & Accountability, authenticity and stakeholder management & 66 & 3. \\
\hline Cluster 5 & Social and financial performance of firms & 64 & \\
\hline Cluster 6 & Labour rights and buyer-supplier relationships & 60 & \\
\hline Cluster 7 & Corporate image and consumer action & 55 & \\
\hline Cluster 8 & Corporate ethical decision making and its consequences & 48 & \\
\hline Cluster 9 & Consumer loyalty and response & 47 & \\
\hline Cluster 10 & Cognitive moral development and ethical behaviour & 46 & \\
\hline Cluster 11 & Ethical issues in the online environment & 45 & \\
\hline Cluster 12 & CSR, fairness issues, and sustainable consumption & 44 & \\
\hline Cluster 13 & The local economy and the business community & 38 & \\
\hline Cluster 14 & Ethical work climate and job satisfaction & 35 & \\
\hline Cluster 15 & Consumer lifestyle, ethical consumption and consumer empowerment & 22 & \\
\hline Cluster 16 & $\begin{array}{l}\text { Corporate strategy, investment decisions, responsible behaviour and } \\
\text { financial returns }\end{array}$ & 21 & $\begin{array}{l}\text { Table II. } \\
\text { Description of the }\end{array}$ \\
\hline Cluster 17 & Ethical orientation of multinational firms & 18 & 17 clusters (step 1$)$ \\
\hline
\end{tabular}

strategy and investment decisions. Finally, cluster 17 is focused on the ethical orientation of multinational firms.

To a researcher who is new to this body of literature, the above list of research areas may already represent a fruitful starting point. If one of the themes captures the scholar's interest, he/she can now proceed to reading the articles connected to that topic. For example, if the researcher chooses cluster 17 (multinational firms' ethical orientation) as a starting point for further exploration, the corresponding article is Boyd and Webb's (2008) "Interorganizational ethical conflict within alliances: A conceptual framework and research propositions" in the Journal of Business-to-Business Marketing. The articles that correspond to cluster themes can be identified in two ways. The researcher can either search for keywords in the reference manager database created at the beginning of the process (see Figure 1) or he/she can run a query in NVivo. At this stage it is possible to go back to the start of the process and devise a completely new search strategy inspired by one cluster or an article identified through the cluster analysis (see Figure 1).

Part 2 of phase 3 , together with phase 4, has two objectives. The first is to demonstrate how researchers can go deeper into this body of literature through abstract mining by feeding selected concepts into NVivo as nodes. The second is to show how these two software tools (VOSviewer and NVivo) can be used as a creativity trigger for the identification of potentially interesting research questions. As explained in the methods section and as is also apparent from Figure 1, the starting point for this NVivo analysis was the list of concepts generated in part 2 of phase 3 . The list was complemented with additional concepts that appeared to be significant. Whether a term or concept was deemed as potentially significant was decided based on the label and density views or in terms of the frequency of their occurrence in the abstracts (determined through the frequency analysis in NVivo). It must be noted that this analysis could be continued endlessly (see Figure 1). The only limit is the researcher's imagination, time and patience. The examples below represent only a fraction of all the possibilities. 
IMR

33,3

338

For instance, on the periphery of a large VOSviewer map (6,000 concepts) the term "appalling workplace conditions" appeared. To demonstrate the importance of creating larger maps, it must be noted that this term does not appear in the visualisation of the 846 concept. The concept "appalling workplace conditions" was subsequently turned into a node (code) in NVivo. After running a query, the abstract containing the search term was identified. Based on their findings, the authors of the identified paper suggest that "organizations should adopt employee rights protection to improve their corporate reputation and financial performance" (see Lee et al., 2013). This sentence triggered the question of which other factors might have an impact on corporate reputation. Figure 3 shows the results from an extended NVivo analysis that also includes the literature sources. This map can serve as the starting point for a more in-depth literature review and/or for theorising. Possible questions to explore could be: Is abusive leadership solely driven by a profit motive? What other factors are there? Do consumers see through empty CSR promises?

From both the cluster analysis (see Table II) and from scrolling in on the density map in VOSviewer (see Figure A1) it is apparent that consumption is an important concept in this literature body. A deeper analysis in NVivo resulted in the node structure represented graphically in Figure 4. A possible research question and a starting point for further exploration could be the following:

$R Q 1$. What is the conceptual difference between all these different kinds of consumption?

$R Q 2$. How is socially responsible consumption different from mindful or sustainable consumption?

$R Q 3$. Is voluntary simplicity connected to the mindfulness of consumers?

$R Q 4$. What are the drivers of ethical and mindful consumption?

RQ5. Can a consumer be mindful and at the same time unethical?

Another example is connected to theory. Looking at the VOSviewer map, several theories are visible, such as network theory and transaction cost economics. Cluster 3 in Table II includes topics related to theory development. This observation inspired the idea of trying to identify the theories that have been used in this body of literature. It must be noted that the analysis here is limited to information contained in the abstracts of papers. Nevertheless, it provides a good starting point for learning about the theories employed in ethics-related marketing papers. Running a search query in NVivo yielded a long list of theories, 44 in total. Figure 5 provides an overview, including the sources that mentioned them. In this way one can see which theories have been used in the same paper. The next step could involve a more in-depth exploration of these theories, their underlying assumptions, and their context. Potential questions and research ideas could be the following: What other theories have been used in (international) marketing management? Where did these theories come from? Which theories were developed within marketing research and which were imported? Were those theories that were conceived outside of (international) marketing imported correctly? That is, did the authors consider their context and underlying assumptions (see Zahra, 2007)?

As the specified area of enquiry concerned ethics and marketing, a palpable question is how the concept of ethics is used in this body of literature. Figure 6 provides an overview of the NVivo analysis. The analysis uncovered the following areas: the institutionalisation of ethics in the form of standards, policies, cultural norms, etc.; ethical misconduct; 


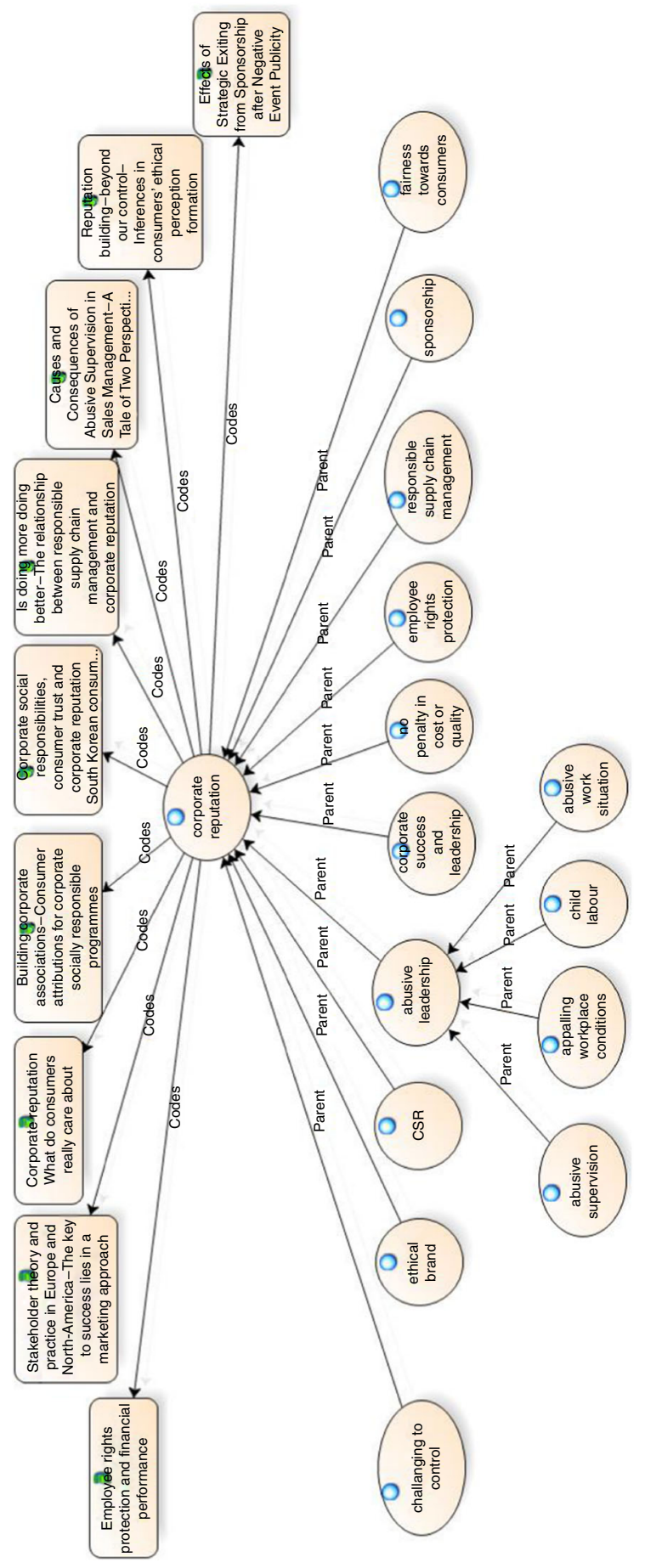

Foundations for theorising

339

Figure 3.

NVivo analysis of the concept "corporate reputation" 
IMR

33,3

340

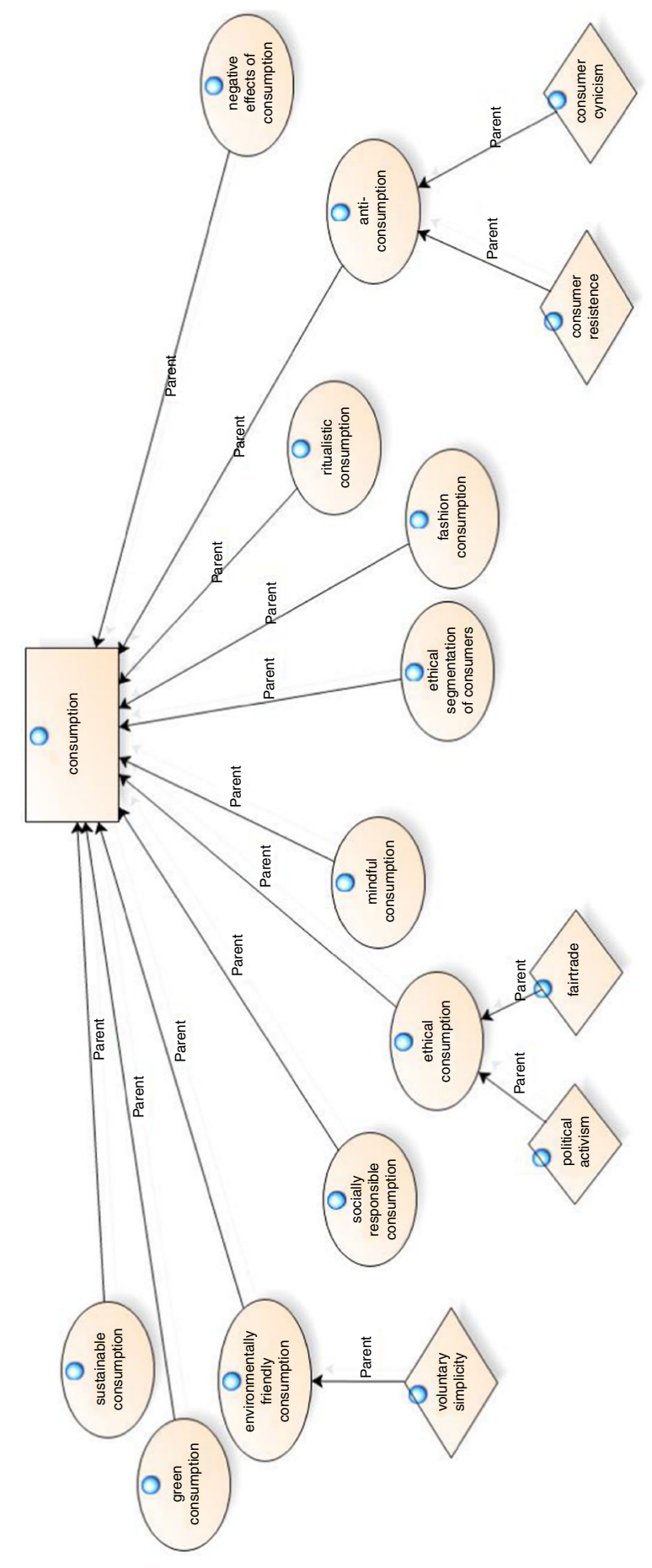

Figure 4.

NVivo analysis of the concept "consumption" 


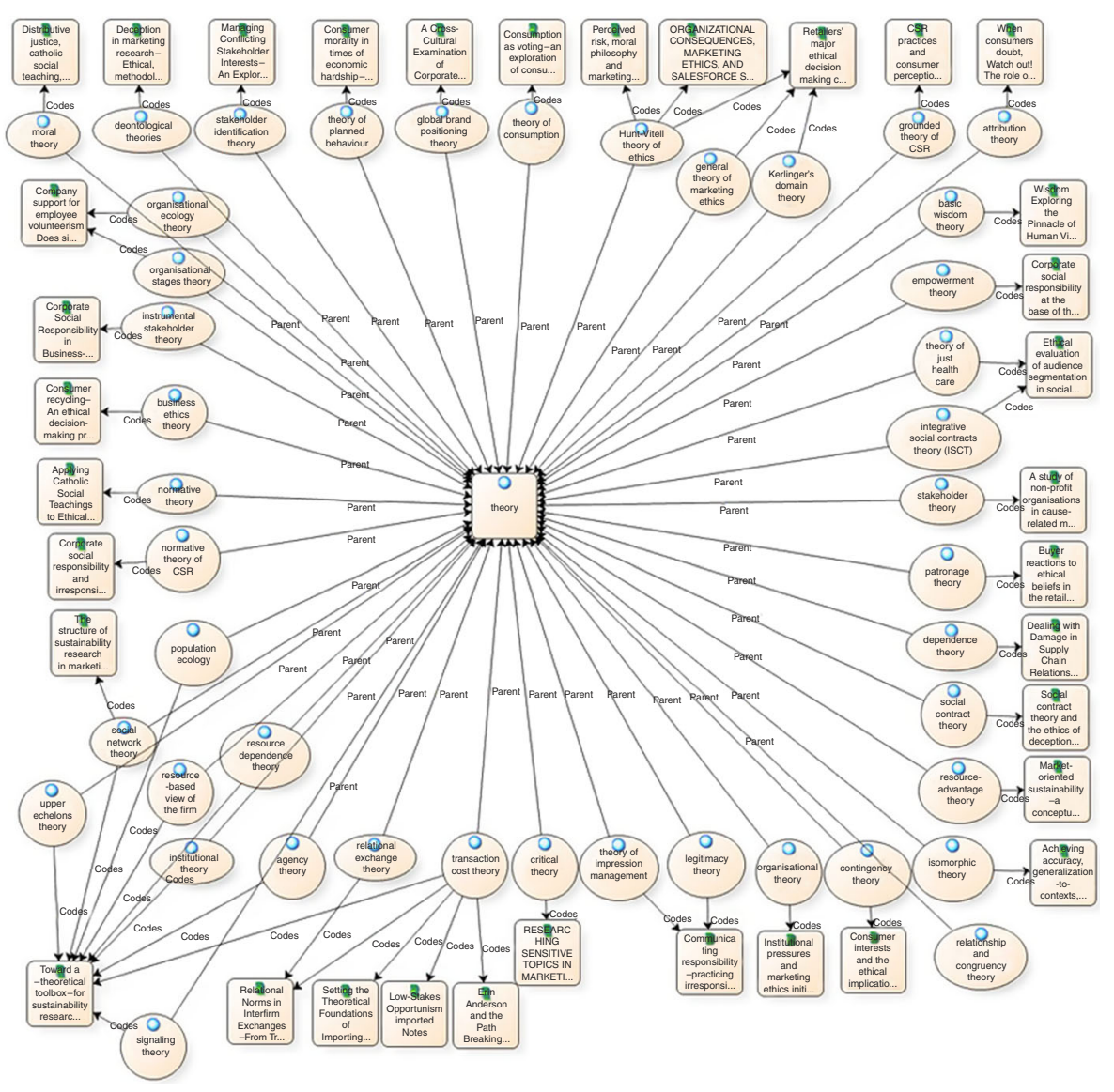

\section{Foundations for theorising}

Figure 5. NVivo analysis of the theories used in the selected literature body

advertising ethics; ethical perspectives on FDI; consumer-related issues; cultural contextualisation; fairtrade; ethics for political marketing; the ethical decision-making process; the ethics of representation; the role of religion; and ethics frameworks. Due to complexity reasons the sources have not been included in the graphical representation. The category "ethical misconduct" can be broken down into sub-categories such as ethical misconduct in marketing research, ethical misconduct of organisation, ethical misconduct of marketers, and ethical misconduct in value and supply chains. Ambush marketing, guilt appeal, fear appeal, covert and stealth marketing have been uncovered as techniques used by unethical marketers. The researcher could take this as a starting point for going deeper into this area and exploring the conceptual differences between these notions. Also, one could set out to uncover other forms of ethical misconduct. Another avenue worth exploring is in relation to ethical issues in supply and value chains. With respect to ethics frameworks, one could set out to identify and categorise all the ethics frameworks that are used within (international) marketing research.

Along with the term "ethics", "CSR" was part of the initial search strategy. Thus, how the CSR concept is integrated into the (international) marketing literature is an important question. Figure 7 presents the findings from the NVivo analysis. 
IMR
33,3

342

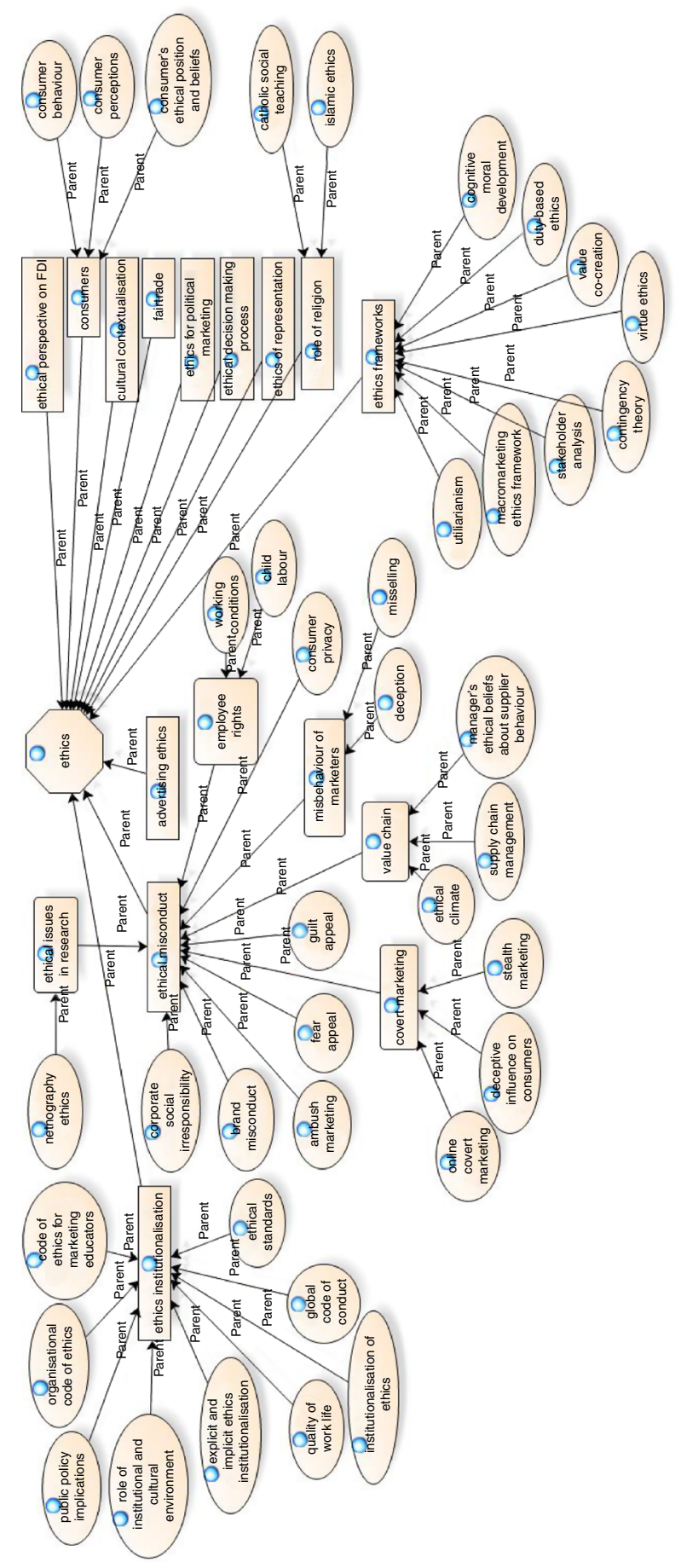

Figure 6.

NVivo analysis of the term "ethics" 


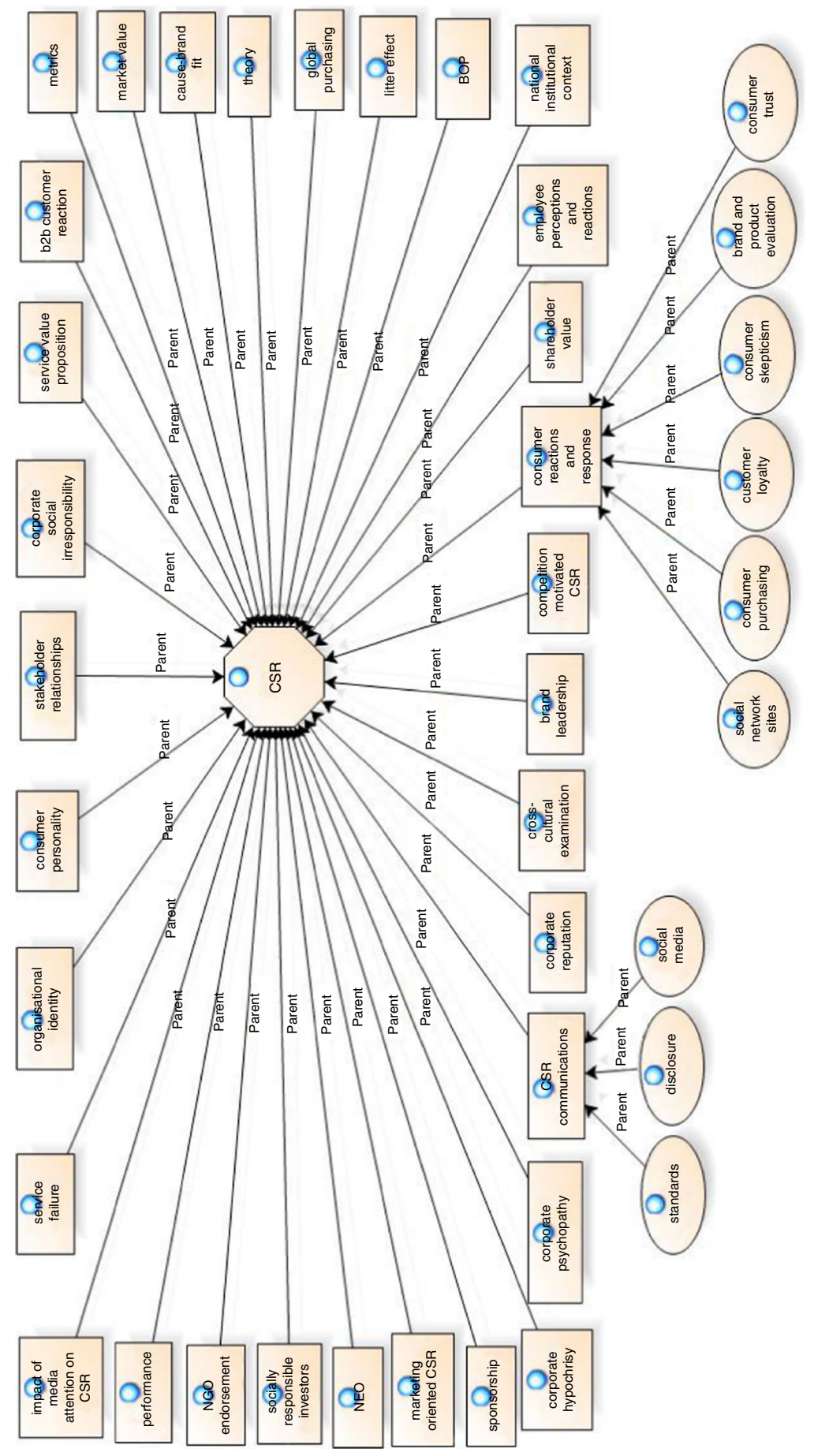

Foundations for theorising

343

Figure 7.

NVivo analysis of the "CSR" concept 
IMR

33,3

344

The three categories that are the most intriguing are "corporate hypocrisy", "corporate psychopathy", and "corporate social irresponsibility". It needs to be noted that the latter sub-category also appeared in the context of ethical misconduct. These three concepts could be an excellent starting point for further explorations into the dark side of CSR. Another potentially interesting research avenue could be an investigation into how consumers are using social media to voice their opinions or to engage in protest against corporations. A similarly interesting research theme could be the exploration of the relationship between the bottom of the pyramid and CSR, that is, the extent to which corporations are hiding their exploitation of bottom-of-the-pyramid consumers behind the mask of CSR.

As stated earlier, the type of playful back-and-forth between VOSviewer and NVivo demonstrated in this section could be carried forth endlessly. However, due to space limitations this section will be concluded with the hope that enough examples have been supplied to demonstrate how these software tools can be used to identify research ideas.

\section{Limitations and future research}

This paper set out to explore two related research questions. That is, how software tools can help reduce the complexity of sifting through large bodies of literature and how these tools can enhance the foundations for theorising. Due to the limited scope of the study, it was not possible to offer a demonstration of how software packages can aid the entire theory construction process. Consequently, future research may wish to go beyond the illustration of the promise of technology for the identification of research questions and offer a detailed account of how technological advancements can contribute to theory building from the beginning to the end.

Another limitation of the current study is that the analysis relied on the information provided by the authors in the abstracts. Future research may want to extend the analysis to the full papers. Future research may also wish to discuss how co-citation analysis in addition to the visualisation of concepts can contribute to the identification of research ideas. Furthermore, future studies could also compare and contrast different software tools and their underlying techniques with respect to their potential to inform the process of theorising.

\section{References}

Altbach, P.G., Reisberg, L. and Rumbley, L. (2010), Trends in Global Higher Education: Tracking an Academic Revolution, UNESCO Pub. and Sense Publishers, Paris, Rotterdam and Boston, MA.

Alvesson, M. and Karreman, D. (2007), "Constructing mystery: empirical matters in theory development", Academy of Management. The Academy of Management Review, Vol. 32 No. 4, pp. 1265-1281.

Backhaus, K., Lugger, K. and Koch, M. (2011), "The structure and evolution of business-tobusiness marketing: a citation and co-citation analysis", Industrial Marketing Management, Vol. 40 No. 6, pp. 940-951.

Baumgartner, H. (2010), "Bibliometric reflections on the history of consumer research", Journal of Consumer Psychology, Vol. 20 No. 3, pp. 233-238.

Bourgeois, L.J. III (1979), "Toward a method of middle-range theorizing”, Academy of Management. The Academy of Management Review (Pre-1986), Vol. 4 No. 3, pp. 443-447. 
Boyd, D.E. and Webb, K.L. (2008), "Interorganizational ethical conflict within alliances: a conceptual framework and research propositions", Journal of Business-to-Business Marketing, Vol. 15 No. 1, pp. 1-24.

Bringer, J.D., Johnston, L.H. and Brackenridge, C.H. (2006), "Using computer-assisted qualitative data analysis software to develop a grounded theory project", Field Methods, Vol. 18 No. 3, pp. 245-266.

Chabowski, B.R., Mena, J.A. and Gonzalez-Padron, T.L. (2011), "The structure of sustainability research in marketing, 1958-2008: a basis for future research opportunities", Journal of the Academy of Marketing Science, Vol. 39 No. 1, pp. 55-70.

Chabowski, B.R., Samiee, S. and Hult, G.T.M. (2013), "A bibliometric analysis of the global branding literature and a research agenda”, Journal of International Business Studies, Vol. 44 No. 6, pp. 622-634.

de Rond, M. and Miller, A.N. (2005), "Publish or perish: bane or boon of academic life?", Journal of Management Inquiry, Vol. 14 No. 4, pp. 321-329.

Dubin, R. (1969), Theory Building, Free Press, New York, NY.

Hoffman, D.L. and Holbrook, M.B. (1993), "The intellectual structure of consumer research - a bibliometric study of author cocitations in the 1st 15 years of the journal of consumer research", Journal of Consumer Research, Vol. 19 No. 4, pp. 505-517.

Jaccard, J. and Jacoby, J. (2010), Theory Construction and Model-building Skills: A Practical Guide for Social Scientists, Guilford Press, New York, NY.

Kaplan, A. (1964), The Conduct of Inquiry; Methodology for Behavioral Science, Chandler Pub., San Francisco, CA.

King, N. (1998), "Template analysis”, in Symon, G. and Cassell, C. (Eds), Qualitative Methods and Analysis in Organizational Research: A Practical Guide, Sage, London, pp. 118-134.

Klavans, R. and Boyack, K.W. (2006), "Quantitative evaluation of large maps of science", Scientometrics, Vol. 68 No. 3, pp. 475-499.

Kopcsa, A. and Schiebel, E. (1998), "Science and technology mapping: a new iteration model for representing multidimensional relationships", Journal of the American Society for Information Science (1986-1998), Vol. 49 No. 1, pp. 7-17.

Lee, N. and Greenley, G. (2009), "What makes a good article? Generating an insightful manuscript”, European Journal of Marketing, Vol. 43 Nos 5/6, pp. 577-582.

Lee, P.K.C., Lau, A.K.W. and Cheng, T.C.E. (2013), "Employee rights protection and financial performance", Journal of Business Research, Vol. 66 No. 10, pp. 1861-1869.

Lindblom, C.E. (1987), "Alternatives to validity: some thoughts suggested by Campbell's guidelines”, Science Communication, Vol. 8 No. 3, pp. 509-520.

Miller, A.N., Taylor, S.G. and Bedeian, A.G. (2011), "Publish or perish: academic life as management faculty live it”, Career Development International, Vol. 16 No. 5, pp. 422-445.

Munoz-Leiva, F., Sanchez-Fernandez, J., Liebana-Cabanillas, F.J. and Martinez-Fiestas, M. (2013), "Detecting salient themes in financial marketing research from 1961 to 2010", Service Industries Journal, Vol. 33 Nos 9/10, pp. 925-940

Richards, L. (1999), Using Nvivo in Qualitative Research, Sage Publications, London, Thousand Oaks, CA and New Delhi, available at: http://public.eblib.com/choice/publicfullrecord.aspx? $\mathrm{p}=456796$

Rosemann, M., Recker, J.C., Indulska, M. and Green, P. (2006), "A study of the evolution of the representational capabilities of process modeling grammars", in Dubois, E. and Pohl, K. (Eds), Advanced Information Systems Engineering - CAiSE 2006, Springer, Luxembourg, pp. $447-461$. 
IMR

33,3

346
Samiee, S. and Chabowski, B.R. (2012), "Knowledge structure in international marketing: a multimethod bibliometric analysis", Academy of Marketing Science. Journal, Vol. 40 No. 2, pp. 364-386.

Shoemaker, P.J., Tankard, J.W. and Lasorsa, D.L. (2003), How to Build Social Science Theories, Sage Publications, Thousand Oaks, CA, available at: http://public.eblib.com/choice/ publicfullrecord.aspx? $\mathrm{p}=996273$

Sinkovics, N. (2013), "Adopting neural net methodology for literature mapping and the generation of research ideas: an example at the interface of entrepreneurship, ICT, and economic development”, in Jean, R.-J., Chiou, J.-S. and Zou, S. (Eds), International Marketing in Rapidly Changing Environments, (Vol. 24), Emerald Group Publishing, Bingley, pp. 103-123.

Sinkovics, R.R., Penz, E. and Ghauri, P.N. (2008), "Enhancing the trustworthiness of qualitative research in international business", Management International Review, Vol. 48 No. 6, pp. 689-713.

Sinkovics, R.R.P. and Alfoldi, E.A. (2012), "Progressive focusing and trustworthiness in qualitative research”, Management International Review, Vol. 52 No. 6, pp. 817-845.

Sutton, R.I. and Staw, B.M. (1995), "What theory is not", Administrative Science Quarterly, Vol. 40 No. 3, pp. 371-384.

Svensson, G. and Wood, G. (2008), “Top versus leading journals in marketing: some challenging thoughts", European Journal of Marketing, Vol. 42 Nos 3/4, pp. 287-298.

van Eck, N.J. and Waltman, L. (2007), "Bibliometric mapping of the computational intelligence field", International Journal of Uncertainty, Fuzziness and Knowledge-based Systems, Vol. 15 No. 5, pp. 625-645.

Van Eck, N.J. and Waltman, L. (2010), "Software survey: VOSviewer, a computer program for bibliometric mapping”, Scientometrics, Vol. 84 No. 2, pp. 523-538.

van Eck, N.J. and Waltman, L. (2015), "VOSviewer manual”, Manual for VOSviewer Version 1.6.1, Universiteit Leiden, Leiden.

Van Eck, N.J., Waltman, L., den Berg, J. and Kaymak, U. (2006), "Visualizing the computational intelligence field application notes", IEEE Computational Intelligence Magazine, Vol. 1 No. 4, pp. 6-10.

Weick, K.E. (1989), "Theory construction as disciplined imagination”, Academy of Management. The Academy of Management Review, Vol. 14 No. 4, pp. 516-531.

Weick, K.E. (1995), "What theory is not, theorizing is", Administrative Science Quarterly, Vol. 40 No. 3, pp. 385-385.

Zahra, S.A. (2007), “Contextualizing theory building in entrepreneurship research”, Journal of Business Venturing, Vol. 22 No. 3, pp. 443-452.

Zhu, W.J. and Guan, J.C. (2013), “A bibliometric study of service innovation research: based on complex network analysis”, Scientometrics, Vol. 94 No. 3, pp. 1195-1216. 
(1) 14,747 (TS = marketing AND TS $=$ (ethics OR ethical) OR TS $=$ ("corporate social responsibility" OR "CSR") OR TS = "human rights") AND LANGUAGE: (English) AND DOCUMENT TYPES: (Article) Indexes $=$ SSCI Timespan $=$ All years

(2) 410 (TS = marketing AND TS $=$ (ethics OR ethical) OR TS $=$ ("corporate social responsibility" OR "CSR") OR TS = "human rights") AND LANGUAGE: (English) AND DOCUMENT TYPES: (Article) AND SOURCE TITLES: (JOURNAL OF BUSINESS RESEARCH OR JOURNAL OF PUBLIC POLICY MARKETING OR EUROPEAN JOURNAL OF MARKETING OR JOURNAL OF MARKETING OR JOURNAL OF THE ACADEMY OF MARKETING SCIENCE OR JOURNAL OF MACROMARKETING OR PSYCHOLOGY MARKETING OR INDUSTRIAL MARKETING MANAGEMENT OR INTERNATIONAL JOURNAL OF CONSUMER STUDIES OR INTERNATIONAL MARKETING REVIEW OR JOURNAL OF ADVERTISING OR JOURNAL OF SERVICES MARKETING OR INTERNATIONAL JOURNAL OF RESEARCH IN MARKETING OR JOURNAL OF ADVERTISING RESEARCH OR JOURNAL OF MARKETING RESEARCH OR JOURNAL OF INTERNATIONAL MARKETING OR JOURNAL OF CONSUMER AFFAIRS OR JOURNAL OF RETAILING OR INTERNATIONAL JOURNAL OF ADVERTISING OR JOURNAL OF CONSUMER PSYCHOLOGY OR ADVANCES IN CONSUMER RESEARCH OR JOURNAL OF BUSINESS-TO-BUSINESS MARKETING OR JOURNAL OF CONSUMER BEHAVIOUR OR MARKETING THEORY)

Table AI. Search strategies

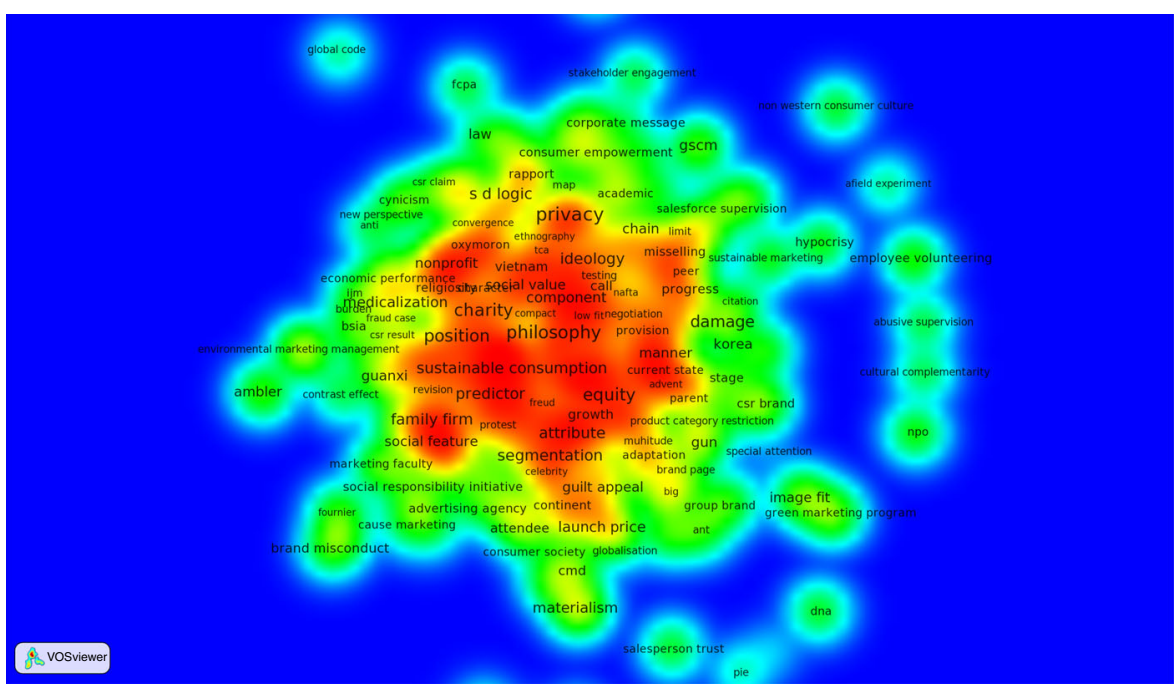

Figure A1.

Density view of the visualisation of 6,000 concepts (full counting) 
Authenticity

Bottom of the pyramid

Consumption

Anti-consumption

Boycotting

Consumer cynicism

Consumer resistance

Environmentally friendly consumption Voluntary simplicity

Ethical consumption

Fairtrade

Political activism

Ethical segmentation of consumers

Fashion consumption

Green consumption

Mindful consumption

Negative effects of consumption

Ritualistic consumption

Socially responsible consumption

Sustainable consumption

Effective communication strategies

Corporate reputation

Abusive leadership

Challenging to control

Corporate success and leadership

CSR

Employee rights protection

Ethical brand

Fairness towards consumers

No penalty in cost or quality

Responsible supply chain

management

Sponsorship

Crime

CSR

$\mathrm{B} 2 \mathrm{~b}$ customer reaction

BOP

Brand leadership

Cause-brand fit

Competition motivated CSR

Consumer personality

Consumer reactions and response

Brand and product evaluation

Consumer purchasing

Consumer skepticism

Consumer trust

Customer loyalty

Social network sites

Corporate hypocrisy

Table AII.

Corporate psychopathy
Ethical

185

2 Ethics

38

Advertising ethics

Consumers

Consumer behaviour

Consumer perceptions

Consumer's ethical position and beliefs

Cultural contextualisation

Ethical decision-making process

Ethical misconduct

Ambush marketing

Brand misconduct

Consumer privacy

Corporate social irresponsibility

Covert marketing

Deceptive influence on consumers

Online covert marketing

Stealth marketing

Employee rights

Child labour

Working conditions

Ethical issues in research

Netnography ethics

Fear appeal

Guilt appeal

Misbehaviour of marketers

Deception

Misselling

Value chain

Ethical climate

Manager's ethical beliefs about supplier behaviour

Supply chain management

Ethical perspective on FDI

Ethics for political marketing

Ethics frameworks

Cognitive moral development

Contingency theory

Duty-based ethics

Macromarketing ethics framework

Stakeholder analysis

Utilitarianism

Value co-creation

Virtue ethics

Ethics institutionalisation

Code of ethics for marketing educators

Ethical standards

Explicit and implicit ethics institutionalisation

Global code of conduct

Institutionalisation of ethics

5

7

2

1

4

1

8

0

1

1

1

1

3

1

1

1

1

1

1

5

1

1

1

7

5

1

3

1

1

1

1

1

0

2

1

1

2

2

NVivo node 


\begin{tabular}{|c|c|c|c|c|}
\hline Name & Sources & Name & Sources & Foundations \\
\hline Corporate reputation & 3 & Organisational code of ethics & 2 & \\
\hline Employee rights protection & 1 & Public policy implications & 1 & \\
\hline Corporate social irresponsibility & 4 & Quality of work life & 3 & \\
\hline Cross-cultural examination & 3 & Role of institutional and cultural environment & 3 & \\
\hline CSR communications & 6 & Ethics of representation & 1 & 349 \\
\hline Disclosure & 1 & Fairtrade & 1 & \\
\hline Social media & 1 & Role of religion & 1 & \\
\hline Standards & 2 & Catholic social teaching & 1 & \\
\hline Employee perceptions and reactions & 3 & Islamic ethics & 1 & \\
\hline Global purchasing & 1 & Human rights & 2 & \\
\hline Impact of media attention on CSR & 1 & Human welfare & 1 & \\
\hline Litter effect & 1 & Legitimacy & 1 & \\
\hline Market value & 1 & Metaphysical & 2 & \\
\hline Marketing-oriented CSR & 1 & Mindfulness & 2 & \\
\hline Metrics & 1 & Morality & 2 & \\
\hline National institutional context & 2 & Neuroscience & 1 & \\
\hline NEO & 1 & Posthumanism & 1 & \\
\hline NGO endorsement & 2 & Humanness & 1 & \\
\hline Organisational identity & 1 & Poverty & 6 & \\
\hline Performance & 2 & Privacy rights & 8 & \\
\hline Service failure & 1 & Advertising & 1 & \\
\hline Service value proposition & 1 & Information technology & 6 & \\
\hline Shareholder value & 1 & Neuromarketing & 1 & \\
\hline Socially responsible investors & 1 & Religion & 4 & \\
\hline Sponsorship & 3 & Catholic social teaching & 1 & \\
\hline Stakeholder relationships & 2 & Islamic ethics & 1 & \\
\hline Theory & 5 & Victim & 1 & \\
\hline Critical management perspective & 1 & & & \\
\hline Theory & 35 & Theory continued & & \\
\hline Actor network theory & 1 & Organisational theory & 1 & \\
\hline Agency theory & 1 & Patronage theory & 1 & \\
\hline Attribution theory & 1 & Population ecology & 1 & \\
\hline Basic wisdom theory & 1 & Relational exchange theory & 1 & \\
\hline Business ethics theory & 1 & Relationship and congruency theory & 1 & \\
\hline Contingency theory & 1 & Resource dependence theory & 1 & \\
\hline Critical theory & 1 & Resource-advantage theory & 1 & \\
\hline Deontological theories & 1 & Resource-based view of the firm & 1 & \\
\hline Dependence theory & 1 & Signalling theory & 1 & \\
\hline Empowerment theory & 1 & Social contract theory & 1 & \\
\hline General theory of marketing ethics & 1 & Social network theory & 2 & \\
\hline Global brand positioning theory & 1 & Stakeholder identification theory & 1 & \\
\hline Grounded theory of CSR & 1 & Stakeholder theory & 1 & \\
\hline Hunt-Vitell theory of ethics & 3 & Theory of consumption & 1 & \\
\hline Institutional theory & 1 & Theory of impression management & 1 & \\
\hline Instrumental stakeholder theory & 1 & Theory of just health care & 1 & \\
\hline Integrative social contracts theory (ISCT) & 1 & Theory of planned behaviour & 1 & \\
\hline Isomorphic theory & 1 & Transaction cost theory & 5 & \\
\hline Kerlinger's domain theory & 1 & Upper echelons theory & 1 & \\
\hline Legitimacy theory & 1 & Organisational ecology theory & 1 & \\
\hline Moral theory & 1 & Organisational stages theory & 1 & \\
\hline Normative theory & 1 & & & \\
\hline Normative theory of CSR & 1 & & & Table AII. \\
\hline
\end{tabular}


IMR

33,3

\section{About the author}

Noemi Sinkovics is a Lecturer in International Business and Management at Alliance Manchester Business School, UK. She received her PhD from The University of Manchester. Her research focuses on domestic and international responsible business practices, social value creation, and on theoretical and practical issues in entrepreneurship and international entrepreneurship. She has contributed book chapters to editions of International Business books and published in International Business Review, International Marketing Review, European Journal of International Management, Journal of Business Research, and Critical Perspectives of International Business. Noemi Sinkovics can be contacted at: noemi.sinkovics@mbs.ac.uk

For instructions on how to order reprints of this article, please visit our website: www.emeraldgrouppublishing.com/licensing/reprints.htm Or contact us for further details: permissions@emeraldinsight.com 